\title{
Towards an Integrative Approach for Teaching Creative Writing in Tertiary Institutions
}

\author{
Acheoah John Emike $(\mathrm{PhD})^{1^{*}}$, Hamzah Abdurraheem $(\mathrm{PhD})^{2}$, Jamilu Mohammed Magaji ${ }^{3}$ \\ ${ }^{1}$ Department of European Languages, Federal University Birnin-Kebbi, Kebbi State, Nigeria \\ ${ }^{2}$ Department of Languages (English Unit), Al-Hikmah University, Ilorin, Nigeria \\ ${ }^{3}$ Federal University Birnin-Kebbi, Kebbi State, Nigeria
}

DOI: 10.36348 /SIJLL.2019.v02i09.002 $\quad$ | Received: 01.11.2019| Accepted: 08.11.2019| Published: 12.11 .2019

*Corresponding author: Acheoah John Emike (PhD)

\section{Abstract}

This study proposes an Integrative Approach to the teaching of creative writing in tertiary institutions across the world. Exploring theoretical perspectives in the literature as they apply to writing in general and literary genres in particular, this study presents tips for better teaching - and invariably, learning of creative writing. In different parts of the world, the Curriculum of Creative Writing in tertiary institutions focuses on literary genres. The French word "genre" denotes "kind" and it is related to "gender" and "genus". As far back as the early nineteenth century the word has been used in English to mean "a kind of literature". The classification of literature into the three basic genres: drama, prose and poetry - is based on whether or not a literary work is dialogue, narrative or verse. This study concludes that creative writing presupposes the use of writing conventions as well as individualistic creative prowess, to make the teaching of discrete skills of creative writing effective and fascinating.

Keywords: Creative writing, tertiary institution, integrative approach, genre, drama, prose, poetry.

Copyright @ 2019: This is an open-access article distributed under the terms of the Creative Commons Attribution license which permits unrestricted use, distribution, and reproduction in any medium for non-commercial use (NonCommercial, or CC-BY-NC) provided the original author and source are credited.

\section{INTRODUCTION}

In higher institutions across the world, creative writing is offered by students, and they are taught the skills for writing across genres, particularly in the basic literary genres: drama, poetry and prose. This paper examines theoretical perspectives in the literature as it attempts to discuss tips for teaching the art, creative writing. To understand creative writing, the term writing has to be understood. Freeman [1] defines writing as "the ability to select the strongest words, the most useful facts since it is the appropriate selection of these facts that engrave the image of a work in the reader's mind." Stanley Oriola, cited in Ayodabo and Demola Jolayemi [2] notes that if writing is to be properly done, certain skills are necessary:

(a) Mental: This requires that a writer must be able to think clearly and be logical, sequential and coherent in how he organizes his ideas.

(b) Psychological: Ideas can only move freely within the various sensitive components of the human system, if a writer is emotionally stable and relaxed. (c) Rhetorical: Writing, like every other practice, has its own rules. A writer must know the rules that are fundamental to his craft; or, else, the semantic depth expected of the work of such a writer will be missed so long as the structural order is flouted. This may result in expressions that are linguistically awkward or syntactically odd. A good writing must make a smooth, flow and 'floody' reading.

(d) Critical: A writer is expected to re-read a work, which he has completed. Beyond this, one should be able to judge or criticize a completed work so as to improve it; thus writing is essentially re-writing. Trask [3] observes that language, which differentiates man from other creatures, is the tool for writing. According to Babatunde [4] writing is a process (a step-by-step activity) and an interaction. Anko [5] notes that "the act of writing consists of stages, with the emphasis now shifted from product-oriented approach to processoriented approach.” Language skills include: listening, speaking, reading and writing. While listening and speaking are receptive skills, speaking and writing are productive skills.

Creative writing is the use of appealing written communication in the transmission of messages. 
Creative writing is an avenue for self-expression and originality. The Curriculum of Creative Writing is usually clear on the goals of the course work. Consider that of Nigerian universities:

This course is designed to stimulate the creative potentials of the students. It will provide instructions on imaginative writing with specific reference to poetry, drama and prose. To be run on a seminar or workshop basis with available writer leading the discussions.

Self-expression is very crucial in the teaching of creative writing because writers have different mindsets, existential experiences, socio-cultural backgrounds and emotions which they try as much as possible to convey via any of the literary genes, and they enact extensive creativity in the process. Their efforts corroborate The Chambers Dictionary (cf. Adéle Ramet [6]) which defines creative writing as "... having the power to create, that creates, showing, pertaining to, imagination, originality and 'writing' as 'The act of one who writes, that which is written, literary production or composition." For Adéle Ramet [6] creative writing is "having the power to create an imaginative, original literary production or composition." The following section examines the literature in terms of historical and theoretical perspectives.

\section{LITERATURE REVIEW}

To give this study sound theoretical base, the history and theories of creative writing are indispensable.

\section{Historical Perspectives on Creative Writing}

Creative writing began to get recognition when in the 1920s the University of Iowa promoted the teaching of the subject as they contended that the academia can explore the latent talents of those who want to be creative writers worthy of scholarly attention. Creative writing programmes continued to develop in different parts of the world, with emphasis on workshops which promoted the idea of acquiring the craft through various processes in the pedagogical approaches - approaches which make it clear that creative writing courses can be significantly assessed and evaluated to measure individualistic progress of learners. In contemporary times, creative writing is part of the curriculum of tertiary education. This explains why celebrated writers of the basic literary genres (drama, prose and poetry) have emerged on the global stage of literary creativity. Mary Swander et al. [7]. Submits:

"In 2005, creative writing became very famous in higher education. In the UK, degrees (MA, MPhils, and PhDs) are now awarded in different aspects of creative writing: poetry, prose, playwriting, science, critical theory, journalism or creative writing pedagogy. The field is fast undergoing innovations even in classroom approaches... until around 1990, most creative faculty followed the Engle teaching model without much reflection. A workshop teacher led small groups - The AWP Directors' Handbook ... recommends no more than fifteen, with twelve as ideal, but recognized that most workshop groups now are between eleven and twenty - through peer oral critiques of completed poems, stories, chapters of novels or plays. In the Engle model, the criticism was meant to be tough and could save the writer years of individual trial and error ... different institutions taught creative writing in one form or the other, using one approach or the other, as the field flourished internationally. This development informed the various workshops, lectures and groups that were instrumental in the enhancement of the teaching and learning of creative writing. Such institutions include: Cardiff University, Antioch University of Los Angeles, Indiana University, and The Iowa Writers' Workshop, among others. The growth of creative writing has culminated in the publication of relevant textbooks on techniques for the skills. According to the AWP Directors' Handbook, undergraduate course in creative writing include craft texts and literary texts: anthropologies, books by single authors, literary periodicals. Such works contain approaches to creative writing (cf. Mary Swander et al. [7]. Indeed, creative writing has continued to gain relevance in academia.

Jenny Newman [8] submits that "when the first creative writing MA in the UK were founded in the late 1960s and early 70s, many traditional scholars and academics argued that no one could teach the mysteries and fascinating process of literary creativity, and that such courses had no place in a university. Their objectives have been overturned, partly, it must be said, because of student demand for accredited creative writing courses from under-funded and money-hungry universities."

In addition, Lauri Ramey [9] submits that "creative writing as an academic subject developed at approximately the same time as English, and out of the same desire, which was to rectify the 'impracticality' of philology."

\section{Theories of Creative Writing}

Theories of creative writing provide insights on how to write different texts. The insights are explored for pedagogical purposes so that teachers can teach adequately, discrete components of the art in class. It is necessary to study theoretical literature in 
any field of research for illuminating perspectives. Indeed, Adonizio and Laux cited in Mary Swander et al. [7] notes that "to write without any awareness of a tradition you are trying to become part of a would-be self-defeating."

The John Hopkins Guide to Literary Criticism and Theory cf. Mary Swander et al. [7] submits that literary theory "aspires, from Aristotle to Hans-George Godamer to Jacquires Derrida toward a systematic statement of the principles and methods governing interpretation and evaluation..." Some of the theories of creative writing cf. Mary Swander et al. [7] include:

i. The Romantic Myth: This theory holds the view that a writer's talent is inborn and that an individual can explore his/her latent talents in the craft through personal effort rather than expecting the craft to be taught in classroom situations. The theory emphasizes the aesthetics of writing as well as originality.

ii. Bloom and Bate Theory: The theory posits that the literary feat of predating celebrated writers threaten the efforts of contemporary and future writers to achieve originality, and the more the numerical strength of such predating great writers, the greater the threat to new writers' attempts to demonstrate originality.

iii. Compositional Theory: To refute the argument that writing is less difficult than literary study this school, championed by Wandy Bishop, contend that writing courses have content and writing is 'important work'. They propose that creative writing should be treated some way as composition classes, creating room for following or flouting writing conventions.

iv. Non-traditional Academic Approach: This approach advocates for the use of workshops in teaching creative writing. The students' works are subjected to critical evaluation.

v. Critical Theory: It teaches learners the necessity of reflecting on the process, aims, content and style of writing as they interpret the social, philosophical, cognitive and diachronic contexts of already published literary works. This practice helps creative writers to produce novel literature that establishes the link between the past and present.

\section{An Integrative Approach for Teaching Creative Writing in Tertiary Institutions}

In this section, various principles, conventions and methods are examined in terms of how they facilitate the writing of literary texts, hence the term integrative:

\section{Message}

Unless a text contains a clear, important message, it cannot attract the reader's attention. Messages in literary genres are derived from societal phenomena. In teaching creative writing, students should be discouraged from writing message-bereaved texts. Through brainstorming, reading or excursions, significant messages can be gathered by students. Writing should be taught as an activity that must have a theme (message). Jane Rogers [10] presents an elaborate list of possible themes for plotting and structure:

- Rags to riches - the Cinderella plot...

- Love-succeeding after being thwarted...

- Transformation - which may be literal, children growing into adults...?

- Disaster - how does the protagonist cope under ever-increasing pressure?

- Good v. evil ...

- The Outsider - Someone strange comes

- Quest or mission - the protagonist has to find or accomplish something ...

There is therefore an initial experience that predates writing. Even if there are several experiences, there may be peculiar, fascinating, intriguing ones worthy of being articulated into writing. In a particular experience, an aspect or some aspects can be selected, so that the appropriate skill for communicating that experience in prose, drama or poetry can be decided. Because of the importance of ideas in creative writing, opportunities are often given to students to visit places. When the experiences they had gathered from such places sink deep into their memories, it becomes easy for them to choose form and write first drafts. Poor knowledge of subject hinders creative writing. Adéle Ramet [6] presents the following as sources of ideas:

- Watching the world go by: Watch how people behave in everyday situations, jotting down ideas in your notebooks as they occur to you;

- Keeping an eye on the media: Perhaps the riches sources of ideas are newspapers, television and radio;

- Airports, beaches;

- Coaches, buses, planes, ships;

- Cafés and restaurants;

- Personal experiences;

- Clubs;

- Doctors'/dentists' surgeries;

- Hair dressers;

- School playgrounds;

- Station, etc.

\section{Elevated Language}

Language-use in literary writings should be appealing. Students of creative writing should be encouraged to study various texts across genres to get used to how language operates in literary writings. By studying how language is explored and re-invented in 
literary writings, students will be able to demonstrate idiosyncratic competence and creative indulgence. Idiosyncrasy (individuality in language) gives a writer edge over his contemporaries. A prospective creative writer should be well equipped in the vocabulary (diction) of the language being used for writing. Aristotle cited in Lauri Ramey [9] submits that "perfect use of diction presupposes the use of ordinary clear words (which make writing understandable) and strange words (which make writing unique)." A writer's ability to use the right word in the right context depends on his knowledge of the vocabulary of the language being used for the ongoing writing. The task before the literary writer is so enormous that weak language background cannot handle it. Writing a novel, a play or a poem is different from writing ordinary letter. Literary writings demand much creative indulgence, without which they cannot stand the test of time. The goal of creative writers is to give their writings what seems to be eternal relevance. Through vast knowledge of diction, a writer can select for use, any of the dictionary entries for communicating discrete messages: formal use, informal use, colloquial use, regional use (as in American or British spelling or meaning), figurative use, etc.

\section{Using the Human Senses}

Given the nature of literary genres, a writer has to explore the five senses of touch, sound, sight, smell and taste. The depiction of phenomena will continually depend on how much a writer ensures that language used to depict or describe such phenomena is appropriate and sense-evoking from the readers' end.

\section{Immediate and Remote Audience}

The creative writing class should be taught the importance of audience to writing tasks. For example, students have to understand that if a novel is specifically written to satirize corruption, the plot and characterization must be skillfully deployed to achieve this. Consciousness of the function of audience in writing also helps writers decide on language. For example, language in poems written for primary school pupils is expected to be as simple as possible, whereas abstraction in language can be expected in poems written for students of tertiary institutions. Writers want many people to read their works, and to make this happen they articulate audience-driven aesthetics into such works. This view corroborates Mike Harris [11] who opines that "scriptwriters create the interest and attention of an audience mainly through narrative."

\section{Doing versus Saying}

Doing adds intensity to description. It is a technique whereby events are presented in such a way that they unfold, and are understood through the actions of the characters. But saying should also be used in a text to establish variation. Good writing presupposes fusion of these two techniques, but with doing being the most potent of the two in terms of adding flavour to a writing and making it very interesting. Characters' actions help provoke the reactions of readers. Through characters actions, readers can see how such characters engage in conflict and dialogue; how they negotiate issues of love, adventure, revenge, man-hunt, ambition, etc. To describe any scene effectively, the writer has to let his characters set the scene as they interact with the physical context.

\section{Contextualization}

Teachers of creative writing cannot ignore the role of contextualization in good writing. By teaching the class the skills of contextualizing their writings, they acquire the tips for articulating context into writing in terms of period and location. Ample description of context is significant in any creative writing task. The description of physical context is easier when the setting of the text is based on a familiar location. However, context transcends the physical. There is psychological context which should also be skillfully explored in writing.

\section{Characterization}

Characterization is a crucial element of creative writing. A writer should view his or her characters as individuals, so that their differences and similarities can be noticed. Several insights abound in the literature on skillful use of characterization in writing. It is necessary for the creative writing class to be made to understand that fictional characters are usually drawn from people the writer is familiar with. A fictional character may represent the human qualities of several people. To make fictional characters ring true and fascinating, the writer may have to explore his own character traits and extend the traits - or explore his knowledge of how certain people behave. For example, a terrorist will go to the extreme point of wickedness to kill his/her target.

Some ways of revealing characters' are listed below (cf. Jane Rogers [10] :

\section{Physical description}

For example 'the babysitter came to loll in front of the television set - Mrs. Moosup with arms too far for sleeves' ... Note here that one telling detail can be more effective than a page of photographically accurate description. Be wary of over description, and cut down on your use of adjectives.

Action

This example is from True History of the Kelly Gang, and follows a scene in which Ned has just shot two men: 'we knocked up an old man in a night-gown Coulson were his name. I counted cut the price for what we took telling him my name so he could tell Ned Kelly were no thief' ... Quite apart from the curious revelation that he is anxious not to be thought a thief after admitting to being a murderer, not 
how Kelly's admitting to being a murderer, not how Kelly's language reveals his lack of formal education.

Speech

This outburst is from David Lurie in Disgrace: I have not sought counselling nor do I intend to seek it. I am a grown man. I am not receptive to being counseled. I am beyond the reach of counselling ...

\section{Possessions or Setting}

This example is a description of the London room furnished by Nazneen's husband Chanu, in Brick Lane ...:

The carpet was yellow with a green leaf design. One hundred per cent nylon and, Chanu said, very hard-wearing. The sofa and Chairs were the colour of dried cow dung, which was a practical colour. They had little sheats of plastic on the headrests to protect them from Chanu's hair oil.

\section{Thought}

In Valerie Martin's Property the protagonist watches her husband's sadistic sexual exploits with young black boys and reports, 'often, as I look through the glass, I hear in my head an incredulous refrain: This is my husband' ... The character's extreme self-control and her powerlessness to change her situation are succinctly revealed by this thought.

\section{Speech or thoughts of other characters}

Other characters may give their view of this particular character, as in Clear Light of Day:

"Bim watched her sister in surprise and amusement. Was Tara, grown daughter, still child enough to play with a snail?"

\section{Language and Style}

In the first person, the language is the character; but also consider the choice of language you are using about the character in the third person, whether it is colloquial or formal, direct or circumlocutory, etc.

\section{Setting}

Setting in a novel is not background; it is a key vital element. In the best novels, it permeates and determines the character's behaviour. It thwarts or facilitates their actions. It may echo their moods or present an ironic contrast ... Setting may be simply geographical; but more often it is also politics, class, public events, all of which impinge upon the lives of your characters. Setting needs thorough research and convincing writing, even if it is a fantasy setting. See Peter Carey's The Unusual Life of Tristran Smith for a meticulously imagined alternative world, complete with footnotes detailing its history.)

When researching historical setting, first-hand accounts are always the most useful. Look at diaries, letters and travelers accounts ...

It is important to make fictional characters exemplify the readers' everyday experience, and individualistic traits. This makes writing real; that is, stereotypes are useful in characterization - making readers observe in the text, what they already know in society about the attitudes, feelings, appearance, aversion, ambition and mindset of certain individuals in society. To situate characters within certain human behavioural patterns, the readers rely on stereotypes articulated in writing. Stereotyping is essentially ideological; this explains why the cultural backgrounds of characters are inseparable from the process of characterization. A writer is expected to have sufficient knowledge of the culture he/she writes about, as epitomized by the characters. This is what Adele Ramet calls "writing as an insider". To make fictional characters believable, writers explore creative intuitions. For example, the characters can be given a past, contextualized in the larger society, appropriately placed in the plot (story-line) and assigned specific role(s)

To see your character in context as a writer, let the readers know whether the character is:

- a toilsome old fisherman;

- a studious university undergraduate;

- an unlucky job-seeker;

- a hardened high-profile terrorist;

- a handsome overzealous banker;

- a fascinating her.

The readers are aware of behavioural traits to expect from each of the above categories of characters. This implies that the extent to which writing aligns with reality in the real world can be ascertained by readers. Another crucial point to note in the use of characterization in literary writings is that redundant characters should be avoided. Redundant characters are those who do not play roles in the text. As a fascinating hero in a literary text for example, one expects to see him as a triumphant protagonist who surmounted all obstacles to his ambition/adventure. Mike Harris [11] submits that "the principal way we explore character in drama, as in life, is by comparing what people say, with what they do." Therefore, a hero is truly heroic if his words are backed with actions (daring enterprise) in the story or play.

\section{Organization}

Like non-literary texts, literary texts have to be organized. Even if the language of a literary work is very good, poor organization can affect the acceptability or rating of the work. The use of outline facilitates the organization of writing. The outline is a 
framework showing the internal structure of the work being written (skeletal form). Given the fact that the gathering of materials to be articulated into a full work is randomly done, there will definitely be arrangement, re-arrangement (organization) of such materials. Writing tasks presupposed information-gathering, and this process precedes actual writing. For writing to suit audience and subject, it has to be well organized. The outline shows the topic and sub-topics in their coherent, logical sequence. It is subject to modification; that is, writing is a recursive process - as a writer progresses in a particular writing task, new insights emerge as part of the imaginative process. These insights have to be infused (incorporated) into the work to evolve a better text. Emerging insights take writing to unexpected dimension or direction as the writer continues to modify language towards effective communication. For example, objects have to be described according to the space they occupy so that readers can easily visualize the scene (spatial arrangement). Details have to be presented in order of occurrence (chronological arrangement). A writer can decide whether details can move from least important to most important or the reverse (climax or emphasis). While some writers present their story from the general to the specific, there are writers who, as a matter of individuality in style, present their story from the specific to the general. Whatever the approach, it should be noticeable by the reader. Events can also be presented by using causeeffect paradigm. A literary text should show: unity (i.e. the parts should cohere); continuity (i.e. the reader should be able to notice the line of thought/the plot); progression (the plot should increase in message). Jane Rogers [10] rightly notes that "plot and structure often change as a novel grows. But it is still necessary to know what they are from the beginning: if writing the novel is a journey of exploration, then the plot and structure you have in your head at the beginning is your map ..."

Organizing a literary text presupposes good knowledge of the term structure. Consider an elaborate view from Jane Rogers:

"Structure is the shape of the book; baldly, It is the order in which the plot is told, which may be chronologically, or backwards in flashbacks, or from the point of view of a minor player, or through conflicting points of view, or counterpointed with another story (or stories) altogether. It is composed of sequences of writing in which contrasts of pace and tension, comedy and tragedy, action and reflection, lead the reader through range of emotions, always asking questions.

It is something the reader needs to be aware of from the start, but is infinitely open to change. It is perfectly possible to write a book and completely change its structure when it is finished. For example, a novel may consist of two characters' contrasting views of love affair; first, one, then the other. It could be restructured by chopping them up, re-ordering, and intercutting the two voices, with an eye to varying pace and increasing suspense. For the novelist at the beginning of a novel, an idea of structure is vital because it breaks the novel into manageable chunks. It is difficult to sit down and write a novel. It is less difficult to sit down and write a ten-page chapter. Invent a structure to begin with, even if you need to change it as you go along ... The five-point structure pattern for novel which is most frequently cited goes: (1) inciting incident, (2) major climax ..., (3) midpoint crisis where underlying motives are revealed, (4) climax, (5) resolution.

I am not recommending a novel to this formula. But applying it to a first draft can help to diagnose problems ..."

\section{Originality}

The scholarly worth of a literary text can be ascertained through its originality. Individuality in language and style are part of originality. Being original does not mean certain writers have not been influenced by the works of predating writers. Corroborating this view, Lauri Ramey [9] notes that "Aristotle's view of originality acknowledges the modification of conventions of writing - such modification, though may be amazing, should be consistent in style. Scholars have different views on originality, particularly because no writing can truly be new. Even Shakespeare is believed to have modified other literary works. For example, Lauri Ramey [9] submits extensively:

Shakespeare himself stole the plot of King Lear from other versions that already existed. This shocks us today where we view 'originality' as the hallmark of literary creativity. But Young himself wrote as late as 1759 that he had seen nothing previously written on the concept of literary originality. Shakespeare did something quite traditional by sending the Cinderella myth and shocked his audience by giving it a tragic ending, which presumably he believed reflected his era. When Bond wrote Lear in 1971, he was performing the same traditional literary operation as Shakespeare. The plays of Bond and Shakespeare are part of a tradition of authors and texts speaking to each other through allusion, one of the most ancient literary tropes."

\section{DISCUSSION AND CONCLUSION}

Writing is conventional as evident in writers' use of language and style across genres. Other genres of 
writing besides literary genres are: journals (any written $\log$ ); diary (a compendium of events of one's life, written daily); essays; memoir (account of specific personal experiences rather than a complete account of one's life experiences); letters (e.g. to the editor of a newspaper); and speeches. However, in this paper, the basic literary genres: drama, prose and poetry - are the focus.

Drama originates from ritual. Mike Harris [11] notes that "drama explores character and ideas through the medium of events generally in the following way: when characters confront obstacles they have to act (or not act) in one way or another. The choice they make reveals them. We think Macbeth is a loyal subordinate but when ambition overcomes the obstacle of his conscience, he kills the king and we realize he's not so loyal after all." Conflict is the core of drama. This explains why according to Mike Harris [11] "the more 'story events' in a script, the more obstacles we see a character dealing with and the more various, the more we are likely to understand (or be puzzled by) him, and the more liable we are to ask questions..." Obstacles in story events transcend the physical. They may take the form of interpersonal conflicting desires. Scenes and sequences are elements of drama.

Prose is a narrative. Persons, places or phenomena are adequately described in prose works depending on the writer's mastery of the language. Consider the ample description below which make the reader feel the writer's past memories:

"But for the moment I would go into the hut only in order to take my clothes off: my grandmother felt that after walking from Kouroussa, the first thing to do was to give myself a bath. She wanted me at least to start my visit clean, though she had no illusions about how long such cleanliness would last; so she would take me straight way to the washplace, a small enclosure near the hut, surrounded by a reed fence and paved with large stones. Then she would go back to the hut, take the pot from the fire, and pour the hot water into a calabash. After she had cooled it to the right temperature, she would carry it into the wash-place. There she would soap me from head to foot with black soap, then rub me roughly down with a sponge made of tow from the dried sterns of pulpy plants. I would leave the hut, all shinning with wet, my blood racing under my gleaming skin, my hair black as pitch, and run to dry myself in front of the fire."

(Camara Laye [12] - The African Child

Poetry is a unique literary genre as a result of language-use and organization. Presented in verse and stanza, poetry is known for abstraction in language use.
The language is usually elevated and enchanting. Sean O’ Brien [13] submits:

"It is in the nature of poetry that the attempt to define a poem remains unfinished. The place to begin is by reading Aristotle's Poetics (cf. $350 \mathrm{BC}$ ), after which there is a vast body of description and analysis from which a number of phrases have entered common usage, including 'emotion recollected in tranquility', 'memorable speech', 'objective correlative', 'what oft was thought but ne'er so well expressed' and 'imaginary gardens with real toads in them'."

Sean O' Brien [13] states that "the Greek root of the word poem - poiesia - means making, an act dependent on artistry, skill, practice and let it be said a capacity not merely for taking endless pains but for enduring perpetual dissatisfaction."

Writers of creative texts explore the conventions of writing as well as individualistic aesthetic matrix. They do not ignore the principles of communicative writing because the themes they derive from society are what they attempt to convey via literary genres, in which case they try to make their writings easy to mean. Creative writing is a field of research in academia. As a distinct field of study, it has evolved scholars whose published works have enriched the literature. See Steven Earnshaw [14] for insights on this claim. Although some scholars contend that the ability to write creatively is inborn, they acknowledge that nevertheless, such skills can be taught and learnt in formal instructional setting (classroom). Literary texts present man's everyday experiences.

In this study, insights into an integrative approach to the teaching of creative writing have been highlighted and discussed with a view to improving the pedagogical process. Conclusively, it is clear that by fusing conventions with authorial goal-driven approach/style writers achieve success in teaching the art, creative writing.

\section{REFERENCES}

1. Freeman, W. (1967). Writing without teachers. London: Oxford University Press.

2. Ayodabo, A., \& Jolayemi, D. (Eds.). (2008). Effective communication skills for higher education: the use of English. Oyo: Ajayi Crowther University.

3. Trask, R. L. (1995). Language: the basics. London and New York: Rouledge.

4. Babatunde, S. T. (1998). Developing effective writing skills: basic requirements. In J. Berke (Ed.), twenty questions for the writer: a rhetoric with readings. Chicago: Harcourt Brace Jovanavich Publishers.

5. Anko, P. (2004). English in use. Lagos: Free Enterprise Publishers. 
6. Adéle, R. (2007). Creative Writing, $7^{\text {th }}$ Edition. How to Content.

7. Leahy, A., Cantrell, M., \& Swander, M. (2014). Theories of Creativity and Creative Writing Pedagogy. The Handbook of Creative Writing, , 1123.

8. Newman, J. (2007). The evaluation of creative writing at MA level (UK). The handbook of teaching creative writing, 24-86.

9. Earnshaw, S. (2007). The handbook of creative writing. Edinburgh University Press.
10. Earnshaw, S. (2007). The handbook of creative writing. Edinburgh University Press.

11. Earnshaw, S. (2007). The handbook of creative writing. Edinburgh University Press.

12. Camara, L. (1954). The African Child. Great Britain: Fontana Books

13. Sean, O' B. (2007). Introduction to Poetry. In Steven Earnshaw (Ed.), the Handbook of Creative Writing. Edingburg: Edingburgh University Press.

14. Steven, E, (Ed.). (2007). The Handbook of Creative Writing. Edingburg: Edingburgh University Press. 